University of Nebraska - Lincoln

DigitalCommons@University of Nebraska - Lincoln

USDA National Wildlife Research Center - Staff Publications
U.S. Department of Agriculture: Animal and Plant Health Inspection Service

2021

\title{
European Starling Nest-site Selection Given Enhanced Direct Nest Predation Risk
}

Bradley Blackwell

Thomas W. Seamans

Morgan Pfeiffer

Bruce N. Buckingham

Follow this and additional works at: https://digitalcommons.unl.edu/icwdm_usdanwrc

Part of the Natural Resources and Conservation Commons, Natural Resources Management and Policy Commons, Other Environmental Sciences Commons, Other Veterinary Medicine Commons, Population Biology Commons, Terrestrial and Aquatic Ecology Commons, Veterinary Infectious Diseases Commons, Veterinary Microbiology and Immunobiology Commons, Veterinary Preventive Medicine, Epidemiology, and Public Health Commons, and the Zoology Commons

This Article is brought to you for free and open access by the U.S. Department of Agriculture: Animal and Plant Health Inspection Service at DigitalCommons@University of Nebraska - Lincoln. It has been accepted for inclusion in USDA National Wildlife Research Center - Staff Publications by an authorized administrator of DigitalCommons@University of Nebraska - Lincoln. 
Original Article

\title{
European Starling Nest-site Selection Given Enhanced Direct Nest Predation Risk
}

\author{
BRADLEY F. BLACKWELL, ${ }^{\mathbf{1}}$ U.S. Department of Agriculture, Animal and Plant Health Inspection Service, Wildlife Services, National Wildlife \\ Research Center, 6100 Columbus Avenue, Sandusky, OH 44870, USA \\ THOMAS W. SEAMANS, ${ }^{2}$ U.S. Department of Agriculture, Animal and Plant Health Inspection Service, Wildife Services, National Wildlife Research \\ Center, 6100 Columbus Avenue, Sandusky, OH 44870, USA \\ MORGAN B. PFEIFFER, U.S. Department of Agriculture, Animal and Plant Health Inspection Service, Wildlife Services, National Wildlife Research \\ Center, 6100 Columbus Avenue, Sandusky, OH 44870, USA \\ BRUCE N. BUCKINGHAM, U.S. Department of Agriculture, Animal and Plant Health Inspection Service, Wildife Services, National Wildlife \\ Research Center, 6100 Columbus Avenue, Sandusky, OH 44870, USA
}

\begin{abstract}
The European starling (Sturnus vulgaris) is recognized, outside its native range, as an invasive species, and efforts to deter its nesting have generally been unsuccessful. Enhancing perceived risk at the nest site is a little-explored route in developing a nest deterrent. Specifically, nest predation risk affects site selection, reproduction, antipredator behavior, and fitness in nesting birds. We questioned whether perceived predation risk as related to a snake model positioned inside a nest box, in striking form, moving, and present throughout the period of cavity site selection would induce European starlings to avoid or delay nest construction. We conducted our study on the 2,200-ha National Aeronautics and Space Administration Plum Brook Station (PBS), Erie County, Ohio, USA. Our objectives were to examine nest initiation, clutch development, and hatching success by starlings relative to 4 nest-box treatments: moving snake model, movement mechanism only, immobile snake model, and control (empty box). We applied treatments across 120 nest boxes on PBS (30 boxes/treatment) from 15 April through 17 June 2019. We observed no treatment effects on nest initiation or date of nest bowl formation. Starlings occupied (laid $\geq 1 \mathrm{egg}$ ) in $76 \%$ of nest boxes (moving snake model $=22$ boxes, movement mechanism $=25$ boxes, immobile snake model $=21$ boxes, control $=23$ boxes). We observed no effects of treatment on likelihood of starlings laying a clutch, date of first egg, clutch size, or hatching success. We suggest that starlings adapted to perceived risk because models, despite animacy, did not attack. Therefore, snake models, as developed herein, are ineffective starling nesting deterrents. Published 2021. This article is a U.S. Government work and is in the public domain in the USA.
\end{abstract}

KEY WORDS antipredator behavior, cavity-nesting birds, European starling, nest box, perceived direct predation risk, Sturnus vulgaris.

The European starling (Sturnus vulgaris; hereafter, starling) is a secondary cavity nester, and has been considered a competitive threat to indigenous cavity-nesting birds in the United States (Kalmbach and Gabrielson 1921; Brush 1983; Kerpez and Smith 1990; Cabe 1993, 2020; Koenig 2003), as well as a pest species and hazard to aviation safety (Feare 1984). The starling's success as an invasive species is considered to be a consequence of its generalist ecological requirements and its ability to live near and benefit from humans (Kessell 1957, Crick et al. 2002). In particular, the starling makes use of a variety of nest sites, including not

Received: 16 January 2020; Accepted: 25 June 2020

Published: 26 February 2021

${ }^{1}$ E-mail: bradley.f.blackwell@usda.gov

${ }^{2}$ Retired only human structures (Kessell 1957, Feare 1984), but also vehicles (e.g., aircraft; Bridgman 1962, Jackson 2000, Psiropoulos and Selner 2019). Efforts to deter starlings from nesting have, for the most part, proven ineffective (e.g., Seamans et al. 2015; Blackwell et al. 2018, 2020).

Over the past 2 decades, however, wildlife researchers and managers have increasingly focused on species antipredator behaviors as logical steps in developing effective management, both in contexts of conservation and wildlife damage (Blackwell et al. 2012, 2016). One area that holds promise for development of strategies to deter starling nesting (aside from obvious opportunities to control access to structures/vehicles) involves exploiting perceived risk of predation at the nest (Blackwell et al. 2018). The effects of actual or perceived nest predation on antipredator behavior and individual fitness form the basis for a rich literature across taxa (e.g., Martin 1993, Caro 2005, Refsnider et al. 2015, Mainwaring et al. 2017). 
In birds, predation influences nest types and concealment, mating behaviors, and reproductive behavior and physiology (e.g., Ricklefs 1969, 1977; Slagsvold 1982; Lima 1987, 2009; Martin 1988, 1993, 1995; Martin and Briskie 2009). Further, risk varies relative to open-cup, primary cavity, and secondary cavity nesters (Nice 1957; Nilsson 1984; Martin 1993, 1995) as cavity-nesting species generally experience less nest predation (Nice 1957, Martin 1993, Fontaine et al. 2007; see also Mouton and Martin 2018).

Manipulation of perceived risk of nest predation near nest sites has offered insights into bird behavioral and physiological responses (Fisher and Wiebe 2006, Mönkkönen et al. 2009, Zanette et al. 2011, Amo et al. 2017). That said, responses by cavity-nesting bird species to manipulation of perceived nest predation risk, particularly direct predation (i.e., via presence of an actual predator or model effecting perception of immediate lethality; Atwood et al. 2009) and prior to reproduction has received minimal research attention (Fisher and Wiebe 2006, Parejo and Avilés 2011, Ruiz et al. 2018). The degree of bird response to perceived predation risk at a potential nest site during site selection might follow according to predator type and frequency of encounter (e.g., introduction of direct risk; Lima and Dill 1990, Lima 2009), information that could detract from the effectiveness of indirect predator cues (e.g., predator scent) intended to thwart nesting (Blackwell et al. 2018, 2020).

We assessed starling nest site selection relative to prolonged manipulation of perceived direct predation risk at a nest box. Our ultimate goal was to develop a simple manipulation of direct predation risk that might reduce starling deposition of nesting material in aircraft hangars and in flight surfaces of moored or hangered aircraft. Building from approaches in which direct predation risk was manipulated at cavity sites (involving primary and secondary cavity-nesting species; Fisher and Wiebe 2006, Parejo and Avilés 2011, Stanback et al. 2018), we questioned whether perceived predation risk as related to a snake model positioned inside a nest box, in striking form, showing animacy (Greggor et al. 2018; see also Parejo and Avilés 2011, Bogrand et al. 2017, Stanback et al. 2018), and present throughout the period of cavity site selection would induce European starlings to avoid or delay nest construction. Specifically, we predicted that the presence of a moving snake model inside a nest box would result in delayed introduction of nesting material and formation of a nest bowl, because of potential predation risk to the adult (Lima and Dill 1990, Lima 2009, Hua et al. 2014), as compared to the immobile snake model, moving novel object, or empty box. If so, we anticipated that starlings would show delayed clutch initiation (Lima 1987, Martin and Li 1992, Martin 1995, Eggers et al. 2006, Fontaine and Martin 2006). Alternatively, we predicted that starlings would avoid nest boxes treated with a snake model (i.e., show plasticity; Martin and Briskie 2009, Mönkkönen et al. 2009, Zanette et al. 2011, Hua et al. 2013), and nest instead in boxes treated with a novel object or control boxes. We recognized, as well, that predator models can fail to effectively mimic the intended predator. As such, a delay in deposition of nest material would be unlikely. Our objectives were to evaluate perceived nest predation risk by quantifying timing of nest initiation, clutch development, and hatching success (i.e., the maximum number of hatchlings relative to the maximum clutch size) by starlings relative to 4 nest-box treatments.

\section{STUDY AREA}

We conducted our study on the 2,200-ha National Aeronautics and Space Administration Plum Brook Station (PBS), Erie County, Ohio, USA $\left(41.3721^{\circ} \mathrm{N}\right.$, $-82.6803^{\circ} \mathrm{W}$ ), from 15 April through 17 June 2019, during the starling breeding season in northern Ohio. Land cover within PBS was a mix of old field, forest, and anthropogenic structures segmented by numerous access roads (see habitat description by Bowles and Arrighi 2004, Tyson et al. 2011, and Blackwell et al. 2018). In addition to nest boxes (see below), there was starling nesting habitat that included natural cavities (Pfeiffer et al. 2019). During our study, our region experienced on average $9.9^{\circ} \mathrm{C}$ air temperature, and a total of $28.5 \mathrm{~cm}$ rain and $78.2 \mathrm{~cm}$ of snow (National Climate Data Center, Seasonal Climate Report 01, Cleveland, OH, March-31 May 2019.

\section{METHODS}

\section{Design}

As in our most recent studies, we used 120 wooden nest boxes $(28 \times 13 \times 17 \mathrm{~cm} ; 5.1-\mathrm{cm}$ diameter entrance; Blackwell et al. 2018). Each nest box was attached to a utility pole 2.5 to $3.0 \mathrm{~m}$ above the ground, protected with an aluminum predator guard below the box (Blackwell et al. 2018, Fig. 1A), and located approximately $60 \mathrm{~m}$ from the nearest box (based on the closest proximity of a neighboring utility pole, and considering semicolonial habits of the starling; Kessel 1957, Feare 1984). All nest boxes were fitted with a removable lid for efficient nest checks (Blackwell et al. 2018, Fig. 1B). As noted in prior research, because of utility pole availability and location, not all boxes faced the same direction (Seamans et al. 2015, Blackwell et al. 2018). However, cavity entry direction does not affect use of natural cavities (Rendell and Robertson 1994).

Our experimental design comprised 4 treatments $(n=30$ nest boxes/treatment): 1) moving snake model in striking position (Bogrand et al. 2017); 2) immobile snake model of the same design; 3) only the spring mechanism that controlled model movement; and 4) the empty nest box as a control. Because we were limited on space within nest boxes relative to the possibility of crowding a nesting starling, and we wanted to introduce movement to the model, we developed a simple snake model in upright, striking position that was composed of braided, black cord, a spring/dowel, and conical head with eyes (Fig. 1). We based the model on the black rat snake (Pantherophis obsoletus; Weatherhead et al. 2010), an indigenous climbing species and known predator of avian nests, consuming eggs, young, and adults (Kellner and Ritchison 1988, Durner and Gates 1993, Blouin-Demers and Weatherhead 2001, DeGregorio et al. 2015). Model snake presence, posture, head orientation, presence of eyes, and seasonality have been 
(A)

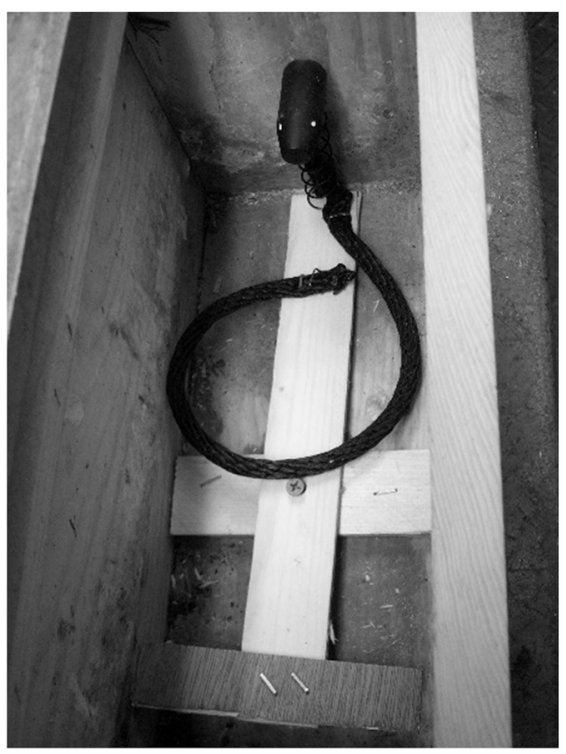

(B)

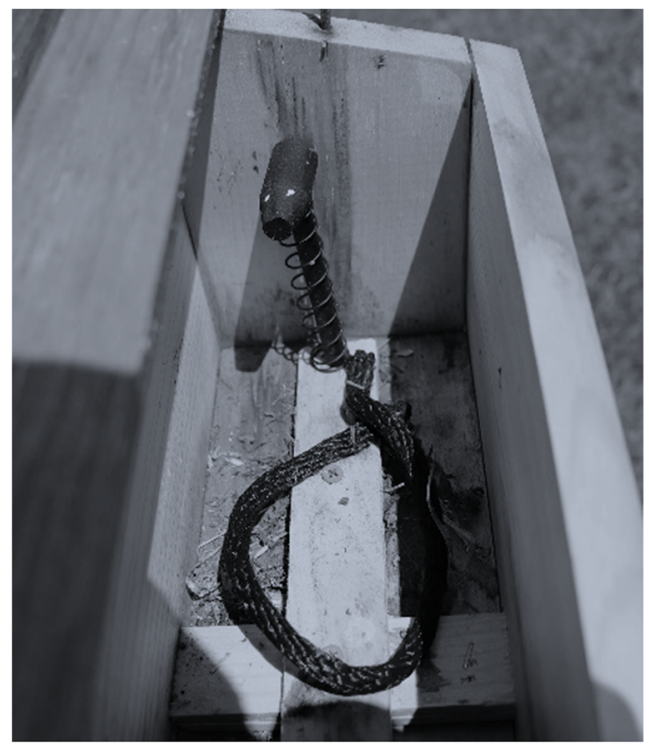

(C)

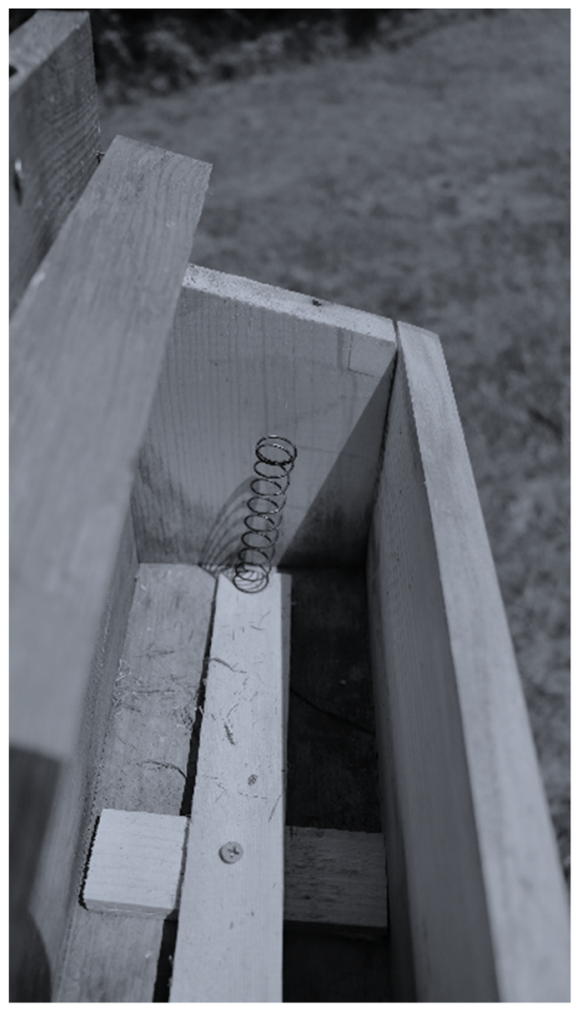

Figure 1. Treatments applied to nest boxes at the National Aeronautics and Space Administration Plum Brook Station (PBS), Erie County, Ohio, USA $\left(41.3721^{\circ} \mathrm{N},-82.6803^{\circ} \mathrm{W}\right)$, in an experiment conducted from 15 April through 17 June 2019, during the starling breeding season in northern Ohio $(n=30$ nest boxes/treatment): A) moving snake mode in striking position; B) immobile snake model of the same design; and C) only the spring mechanism that controlled model movement. An empty nest box served as a control. Snake models were composed of braided, black cord, a spring/dowel, and conical head with eyes. Both the moving and immobile snake models rested on a treadle, but the treadle for the immobile model was secured to the box floor and the upright portion of the body was held in place by a dowel. A 50-g mass was required to tip the treadle, effecting movement of the model.

previously considered in a foraging application to Carolina chickadees (Poecile carolinenesis) and tufted titmice (Baeolophus bicolor); snake head orientation proved the most significant effect on successful foraging, and seasonality had no effect (Cantwell et al. 2016). Further, microclimatic conditions play a role in snake emergence from hibernacula, and black rat snakes have been recorded emerging in the area of the Frontenac Axis, southeastern Ontario, Canada, by mid-April (Blouin-Demers et al. 2000). We recognized, too, that predator size can affect antipredator responses (e.g., relative to the immediacy of the risk and prey age/ development stage; Palleroni et al. 2005, Templeton 
et al. 2005, Beránková et al. 2015). However, as noted above, black rat snakes represent predation risk to eggs, young, and adults, and starlings in our study were exposed to snake models during nest site selection. As such, our models represented potential risk to adults, but also to successful reproduction.

Both the moving and immobile snake models rested on a treadle, but the treadle for immobile model was secured to the box floor and the upright portion of the body was held in place by a dowel (Fig. 1). In contrast, movement in the moving snake model was initiated by the bird entering the box and landing on the treadle; movement required at least a 50 - $\mathrm{g}$ weight on the end of the treadle nearest the entry hole. Movement in predator models has been shown to be effective in stimulating antipredator responses in prey, particularly if the model resembles an object that moves naturally (e.g., jackdaw [Corvus monedula] response to model snake, Greggor et al. 2018). However, prey might also disregard aspects of model shape when exposed to movement in the presence of other cues (e.g., fathead minnow [Pimephales promelas] exposed to conspecific chemical alarm cues and novel or predator-like object shapes that were stationary or moving; Wisenden and Harter 2001).

We randomly assigned a treatment to our first nest box (previously numbered), which subsequently was the moving snake model. We then assigned the spring mechanism to box 2 , thereby avoiding placement of predator models in neighboring boxes. We assigned the immobile snake model to box 3 and the control to box 4 . We systematically repeated this same order of treatment assignments for each consecutive quartet of nest boxes to achieve a sample size of 30 nest boxes per treatment $(N=120$ boxes). Our treatments were not removed from nest boxes until the close of the study.

\section{Protocol}

As noted previously by Blackwell et al. (2018, 2020), starlings in northern Ohio have been found to overwinter (Kessel 1953; TWS, BFB, MBP personal observations). Resident starlings overwintering on breeding grounds will begin to investigate previous and new, candidate nest sites during late winter through early spring (Kessel 1957). During February 2019, all remnant nesting material in nest boxes was removed and all entrances were closed. We placed treatments in nest boxes during March, but did not open nest boxes until 15 April 2019, thus exposing birds to treatment upon initial investigation of box interiors and prior to reproductive commitment.

We inspected each box twice weekly, beginning 18 April. Two teams of observers ( 1 to 2 observers per team) inspected nest boxes (60 boxes per team), beginning at approximately 0730 and continuing through approximately 1100 . We randomly selected the direction of nest box inspection (e.g., box 1 to 120 or the opposite) on the first day and alternated thereafter. The same observers collected data through completion of the study. We recorded the approximate ordinal date of first nesting material, appearance of a nest bowl (Blackwell et al. 2018, 2020), first egg, species, maximum clutch size, and maximum number of hatchlings. Starlings generally lay one egg per day, begin incubation with the next-to-last or last egg laid, and incubate approximately 12 days with young hatching asynchronously (Feare 1984). We estimated date of first egg by subtracting the total number of eggs within a nest when first encountered from the date of the observation (Blackwell et al. 2018, 2020). We followed nests through hatching. Finally, we noted whether a nest appeared to have been abandoned, suffered predation, or there was evidence of infanticide (e.g., eggs or young found at base of the utility pole).

\section{Analyses}

We evaluated the likelihood that first material was deposited in nest boxes and formation of the nest bowl occurred over a period of 14 days since opening nest boxes (Blackwell et al. 2020), respectively, by treatment using a generalized linear model, a binomial distribution, and logit link (PROC GENMOD, SAS 9.2, Cary, NC, USA). The 14-day period was simply an arbitrary index of how treatments might have affected starling early investigations of boxes (Kessell 1957), though species associated with nest material deposition were unknown. Each box was scored as 1 if the respective response variable (i.e., ordinal date) fell within the 2-week period; otherwise the box was scored as 0 .

We also asked whether treatment affected the likelihood of box occupancy (i.e., laying of $\geq 1 \mathrm{egg}$ ) by starlings, again using a generalized linear model, a binomial distribution, and logit link. We then asked whether treatment affected the date of first egg deposition, as well as maximum clutch size. Here, we used a generalized linear model, assumed a Poisson distribution, and log link. Finally, we employed the generalized linear model, with a negative binomial distribution and $\log$ link to examine treatment effects on maximum number of hatchlings. Given our findings, we did not assess treatment effects on hatching success (see below). We examined the Poisson and negative binomial models relative to overdispersion via deviance, Pearson $\chi^{2} / \mathrm{df}$, and probability for the $\chi^{2}$ value. We evaluated the contribution of model parameters to variance in the response variable for each analysis relative to $\alpha=0.05$. Our research protocol (QA-3048) was approved the U.S. Department of Agriculture National Wildlife Research Center's Institutional Animal Care and Use committee.

\section{RESULTS}

We observed nesting material in 117 (97.5\%) nest boxes. Starlings occupied 91 boxes ( 76\% of available nest boxes). Eastern bluebirds (Sialia sialis) occupied (laid $\geq 1 \mathrm{egg}$ ) 7 boxes, tree swallows (Tachycineta bicolor) occupied 16 boxes, and southern flying squirrels (Glaucomys volans) took over 2 boxes. Across starling-occupied boxes, 19 nests were lost to abandonment $(\bar{x}=0.50 \pm 0.58$ [SD] nests/treatment: moving snake model $n=0$; spring mechanism $n=1$; immobile snake model $n=1$; control $n=1$ ), possible predation $(\bar{x}=2.50 \pm 0.58$ nests/treatment: moving snake model $n=3$; spring mechanism $n=2$; immobile snake model $n=2$; 
Table 1. Nesting metrics (SE) and model likelihood results for European starlings and all avian species that selected nest boxes ( $N=120$ boxes; 30 boxes/ treatment) on the U.S. National Aeronautics and Space Administration's Plum Brook facility in Erie County, Ohio, USA, from 15 April through 17 June 2019 and relative to candidate nest-deterrent treatments.

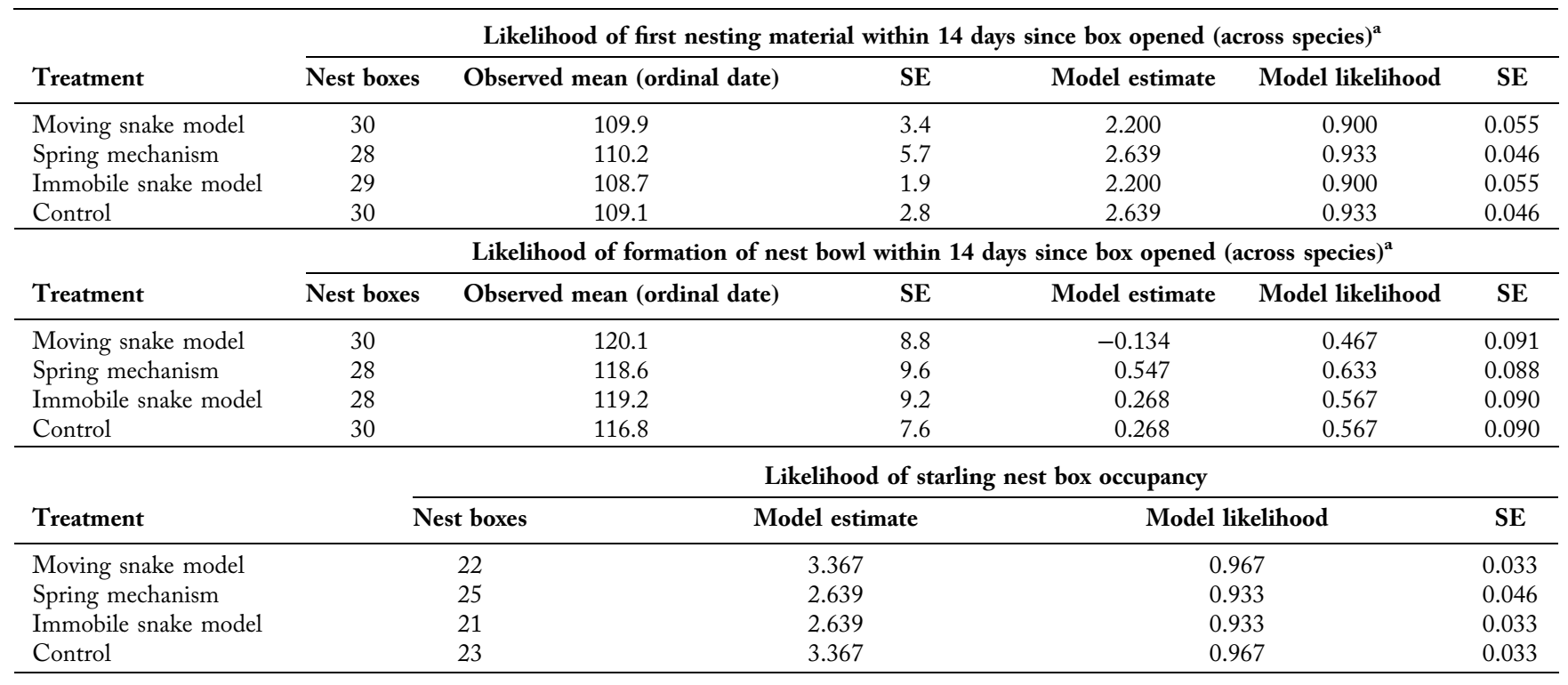

${ }^{a}$ Results based on a generalized linear model with binomial distribution; treatment served as fixed effect.

control $n=3)$, and infanticide $(\bar{x}=1.75 \pm 0.96$ nests/treatment: moving snake model $n=1$; spring mechanism $n=2$; immobile snake model $n=2$; control $n=1$ ).

We observed no treatment effects on likelihood of first nesting material within 14 days since opening the nest boxes $\left(\chi_{3}^{2}=0.44, P=0.93\right.$; Table 1$)$, nor the likelihood of formation of the nest bowl during that period $\left(\chi_{3}^{2}=1.73\right.$, $P=0.63$; Table 1). There was no treatment effect on the likelihood of nest box occupancy by starlings $\left(\chi_{3}^{2}=0.71\right.$, $P=0.87$; Table 1 ), nor was there a treatment effect on date of first egg $\left(\chi_{3}^{2}=2.78, P=0.43\right.$; Table 2$)$, maximum clutch size $\left(\chi_{3}^{2}=1.93, P=0.59\right.$; Table 2$)$, or maximum number of hatchlings $\left(\chi_{3}^{2}=0.64, P=0.89\right.$; Table 2$)$. Finally, our Poisson and negative binomial models showed no overdispersion ( $\chi^{2} / \mathrm{df}$ ranged 0.444-0.939; $P$ ranged 0.640-1.000).

\section{DISCUSSION}

European starlings selecting nest boxes at an experiment site in northern Ohio (April through June 2019) showed no delay in nesting or effects on reproduction when exposed to moving or immobile snake models inside boxes. Weatherhead and Blouin-Demers (2004), in their review of recent studies at that time, suggested that snakes were the most important nest predators for New World Passeriformes.
However, findings from research that manipulated perceived, direct predation risk at the cavity, including snake predation (Fisher and Wiebe 2006, Parejo and Avilés 2011, Stanback et al. 2018), suggest that a broader array of information might weigh on decisions to abandon a cavity. In previous research examining starling nesting in response to indirect predator cues inside and on nest boxes, Blackwell et al. (2020) suggested that direct or indirect experience with nest predation attempts (which enhance perceived risk) and the starling's plasticity in antipredator responses are key hurdles in development of an efficacious nesting deterrent. During our study, despite our use of predator guards below nest boxes to reduce nest losses to predation during the experiment (Blackwell et al. 2018), we cannot dismiss the possibility of actual or attempted snake predation via access points along supporting cables to utility poles or even across the guards themselves (Laskey 1946, Miller 2002). But, because our experimental design did not incorporate sampling via video cameras, we can only speculate as to possible predation events, as well as starling behavior upon encountering snake models used in this study.

It is also conceivable that starlings reacted initially to the snake models, but continued to investigate, possibly because of limited nest site availability. However, in recent research

Table 2. Nesting metrics (SE) for European starlings that selected nest boxes on the U.S. National Aeronautics and Space Administration's Plum Brook facility in Erie County, Ohio, USA, from 15 April through 17 June 2019 and relative to candidate nest-deterrent treatments.

\begin{tabular}{|c|c|c|c|c|c|c|c|}
\hline \multirow[b]{2}{*}{ Treatment } & \multirow[b]{2}{*}{ Nest boxes } & \multicolumn{2}{|c|}{ Ordinal date of first egg } & \multicolumn{2}{|c|}{ Maximum clutch size } & \multicolumn{2}{|c|}{ Maximum number hatchlings } \\
\hline & & Observed mean & $\mathrm{SE}$ & Observed mean & SE & Observed mean & SE \\
\hline Moving snake model & 22 & 122.5 & 7.8 & 4.7 & 1.0 & 3.5 & 1.9 \\
\hline Spring mechanism & 25 & 122.2 & 10.7 & 4.1 & 1.6 & 3.4 & 1.9 \\
\hline Immobile snake model & 21 & 124.4 & 12.3 & 5.0 & 1.2 & 3.2 & 2.0 \\
\hline Control & 23 & 119.0 & 7.5 & 4.5 & 1.6 & 3.1 & 2.0 \\
\hline
\end{tabular}


on PBS starlings nested in $<70 \%$ of available nest boxes (Seamans et al. 2015; Blackwell et al. 2018, 2020). Further, Pfeiffer et al. (2019) showed that an index for natural cavity availability had no effect on starling occupancy of nest boxes on PBS; proximity to human structure, presumably because of mown grass areas, positively influenced occupancy. Moreover, starlings failed to occupy all nest sites in the current study. Therefore, we suggest that nest site availability was not a factor.

However, both the level of perceived predation risk at a treated site and associated risk of a new nest box or cavity site might have affected starling response to our snake models. Specifically, starlings, after initial investigations of the nest boxes, might have perceived minimal or no risk because the models did not effectively attack, despite strikelike movement by the model (Lima and Dill 1990, Bouskila and Blumstein 1992). Fisher and Wiebe (2006) suggested that, in the case of northern flickers (Colaptes auratus), a single encounter with a model predator at the nest site was insufficient to induce site abandonment, given costs associated with cavity construction. Ruiz et al. (2018) reported that southern house wrens (Troglodytes aedon musculus) showed a graded or threat-sensitive response to predator (raptor model) treatments, likely based on direct experience with the predator. But, the authors also reported the absence of differences among treatments in nest visitation by southern house wrens, after resuming parental activities, suggesting a devaluation of threat levels in the raptor models over the period of exposure. Further, Stanback et al. (2018) suggested that remaining at a cavity site where a predator was recently observed was less costly and no more risky than locating a new cavity where predator presence was unknown.

We must also consider whether our snake models were realistic enough to provoke antipredator responses. Specifically, unless a taxidermy mount (e.g., snake; Bogrand et al. 2017; corvid; Němec and Fuchs 2014), models might fail to effectively mimic an actual predator (e.g., from spectral [Blackwell and Fernández-Juricic et al. 2013] and olfactory perspectives [Parsons et al. 2018]). First, to our knowledge, there has been no quantitative consideration of avian response to snake models based on reflected spectra salient to particular bird species (e.g., model vs. actual snake species; Blackwell and Fernández-Juricic et al. 2013), despite multiple studies effectively incorporating various forms of snake model to elicit antipredator responses in birds (e.g., Parejo and Avilés 2011, Cantwell et al. 2016, Greggor et al. 2018, Stanback et al. 2018). Second, avian olfactory capabilities are well developed and used in predator detection (Amo et al. 2011, 2017), and our models did not incorporate actual scent from a black rat snake (e.g., Godard et al. 2007). Again, however, the aforementioned studies using snake models did not incorporate scent. Third, even primitive serpentine forms have stimulated antipredator responses in the common toad (Bufo bufo; Ewert and Traud 1979), and 2-dimensional, monochromatic images in starlings (Belin et al. 2018). Finally, as noted above, model movement might overcome form-related cues, thus stimulating antipredator responses (Wisenden and Harter 2001).

\section{MANAGEMENT IMPLICATIONS}

Moving and immobile snake models placed inside nest boxes failed to deter starlings from nest construction and reproduction. Thus, we cannot recommend use of snake models (as developed herein) in structures or flight surfaces of aircraft to deter deposition of nesting material by nesting starlings. However, future research might consider animate snake models on or near nest boxes and showing attack on a model prey species, as well as variability in both frequency and period of exposure to the treatments.

\section{ACKNOWLEDGMENTS}

The USDA Wildlife Services National Wildlife Research Center (NWRC) provided salaries. R. Iglay and G. Linz provided reviews and helpful comments of earlier versions of this manuscript. A. Bowe provided field support. Funding for data collection was provided by the NWRC. We thank the Wildlife Society Bulletin reviewers for their time and helpful comments.

\section{LITERATURE CITED}

Amo, L., G. Tomás, and A. López-García. 2017. Role of chemical and visual cues of mammalian predators in nest defense in birds. Behavioral Ecology and Sociobiology 71:49.

Amo, L., M. E. Visser, and K. van Oers. 2011. Smelling out predators is innate in birds. Ardea 99:177-184.

Atwood, T. C., E. M. Gese, and K. E. Kunkel. 2009. Spatial partitioning of predation risk in a multiple predator-multiple prey system. Journal of Wildlife Management 73:876-884.

Belin, L., L. Formanek, C. Heyraud, M. Hausberger, and L. Henry. 2018. Influence of early experience on processing $2 \mathrm{D}$ threatening pictures by European starlings (Sturnus vulgaris). Animal Cognition 21:749-758.

Beránková, J., P. Veselý, and R. Fuchs. 2015. The role of body size in predator recognition by untrained birds. Behavioural Process 120:128-134.

Blackwell, B. F., T. L. DeVault, E. Fernández-Juricic, E. Gese, L. GilbertNorton, and S. Breck. 2016. No single solution: application of conservation behaviour principles in mitigating human-wildlife conflict. Invited manuscript. Animal Behaviour 120:245-254.

Blackwell, B. F., and E. Fernández-Juricic. 2013. Behavior and physiology in the development and application of visual deterrents at airports. Pages 11-24 in T. L. DeVault, B. F. Blackwell, and J. L. Belant, editors. Wildlife in airport environments: preventing animal-aircraft collisions through science-based management. The Wildlife Society and Johns Hopkins University Press, Baltimore, Maryland, USA.

Blackwell, B. F., T. W. Seamans, J. L. Belant, K. C. VerCauteren, and L. Tyson. 2012. Exploiting antipredator behavior in white-tailed deer for resource protection. Wildlife Society Bulletin 169:1-8.

Blackwell, B. F., T. W. Seamans, M. B. Pfeffer, and B. N. Buckingham. 2018. European starling reproduction undeterred by predator scent inside nest boxes. Canadian Journal of Zoology 96:980-986.

Blackwell, B. F., T. W. Seamans, M. B. Pfeiffer, and B. N. Buckingham. 2020. Predator scent and visual cue applied to nest boxes fail to dissuade European starlings from nesting. Wilson Journal of Ornithology 132:113-123.

Blouin-Demers, G., K. A. Prior, and P. J. Weatherhead. 2000. Patterns of variation in spring emergence by black rat snakes (Elaphe obsolete obsoleta). Herpetologica 56:175-188.

Blouin-Demers, G., and P. J. Weatherhead. 2001. Habitat use by black rat snakes (Elaphe obseleta) in fragmented forests. Ecology 82:2882-2896.

Bogrand, A. L., D. L. Neudorf, and P. Matich. 2017. Predator recognition and nest defense by Carolina wrens Thryothorus ludovicianus in urban and rural environments: does experience matter? Bird Study 64:211-221. 
Bouskila, A., and D. T. Blumstein. 1992. Rules of thumb for predation hazard assessment: predictions from a dynamic model. American Naturalist 139:161-176.

Bowles, M. D., and R. S. Arrighi. 2004. NASA's nuclear frontier: the Plum Brook reactor facility. Monographs in Aerospace History, Vol. 33. NASA History Division, Office of External Relations NASA Headquarters, Washington, D.C., USA.

Bridgman, C. J. 1962. Birds nesting in aircraft. British Birds 11:461-469.

Brush, T. 1983. Cavity use by secondary cavity-nesting birds and response to manipulations. Condor 85:461-466.

Cabe, P. R. 1993. European starling (Sturnus vulgaris), version 2.0. The birds of North America online. A. Poole, editor. Cornell Lab of Ornithology, Ithaca, New York, USA.

Cabe, P. R. 2020. European Starling (Sturnus vulgaris), version 1.0. The Birds of the World. S. M. Billerman, editor. Cornell Lab of Ornithology, Ithaca, New York, USA. https://birdsoftheworld.org/bow/species/ eursta/cur/introduction. Accessed 5 Jan 2021.

Cantwell, L. R., W. Johnson, R. E. Kaschel, D. J. Love, and T. M. Freeberg. 2016. Predator-risk-sensitive foraging behavior of Carolina chickadees (Poecile carolinensis) and tufted titmice (Baeolophus bicolor) in response to the head orientation of snake predator models. Behavioral Ecology and Sociobiology 70:533-539.

Caro, T. 2005. Antipredator defenses in birds and mammals. University of Chicago Press, Chicago, Illinois, USA.

Crick, H. Q. P., R. A. Robinson, G. F. Appleton, N. A. Clark, and A. D. Rickard, editors. 2002. Investigation into the causes of the decline of starlings and house sparrows in Great Britain. British Trust for Ornithology Research Report 290. Defra, London, England, United Kingdom.

DeGregorio, B. A., J. H. Sperry, M. P. Ward, and P. J. Weatherhead. 2015. Wait until dark? Daily activity patterns and nest predation by snakes. Ethology 121:1225-1234.

Durner, G. M., and J. E. Gates. 1993. Spatial ecology of black rat snakes of Remington farms, Maryland. Journal of Wildlife Management 57:812-826.

Eggers, S., M. Griesser, M. Nystrand, and J. Ekman. 2006. Predation risk induces changes in nest-site selection and clutch size in the Siberian jay. Proceedings of the Royal Society of London B: Biological Sciences 273:701-706.

Ewert, J.-P., and R. Traud. 1979. Releasing stimuli for antipredator behavior in the common toad Bufo bufo (L.). Behaviour 68:170-180.

Feare, C. 1984. The starling. Oxford University Press, New York, New York, USA.

Fisher, R. J., and K. L. Wiebe. 2006. Breeding dispersal of northern flickers Colaptes auratus in relation to natural nest predation and experimentally increased perception of predation risk. Ibis 148:772-781.

Fontaine, J., and T. Martin. 2006. Parent birds assess nest predation risk and adjust their reproductive strategies. Ecology Letters 9:428-434.

Fontaine, J. J., M. Martel, H. M. Markland, A. M. Niklison, K. L. Decker, and T. E. Martin. 2007. Testing ecological and behavioral correlates of nest predation. Oikos 116:1887-1894.

Godard, R. D., B. B. Bowers, and C. M. Wilson. 2007. Eastern bluebirds Sialia sialis do not avoid nest boxes with chemical cues from two common nest predators. Journal of Avian Biology 38:128-131.

Greggor, A. L., G. E. McIvor, N. S. Clayton, and A. Thornton. 2018. Wild jackdaws are wary of objects that violate expectations of animacy. Open Science 5:181070.

Hua, F., R. J. Fletcher, K. E. Sieving, and R. M. Dorazio. 2013. Too risky to settle: avian community structure changes in response to perceived predation risk on adults and offspring. Proceedings of the Royal Society of London B: Biological Sciences 280:20130762.

Hua, F., K. E. Sieving, R. J. Fletcher, Jr., and C. A. Wright. 2014. Increased perception of predation risk to adults and offspring alters avian reproductive strategy and performance. Behavioral Ecology 25:509-519.

Jackson, J. A. 2000. Rapid nest-site selection and initiation of nests on commercial aircraft by European starlings. Migrant 71:97-99.

Kalmbach, E. R., and I. N. Gabrielson. 1921. Economic value of the starling in the United States. Bulletin Number 868. U.S. Department of Agriculture, Washington, D.C., USA.

Kellner, C., and G. Ritchison. 1988. Nesting success and incubation behavior of American kestrels in central Kentucky. Wilson Bulletin 100:317-319.

Kerpez, T. A., and N. S. Smith. 1990. Competition between European starlings and native woodpeckers for nest cavities in saguaros. Auk 107:367-375.
Kessel, B. 1953. Second broods in the European starling in North America. Auk 70:479-483.

Kessel, B. 1957. A study of the breeding biology of the European starling (Sturnus vulgaris L.) in North America. American Midland Naturalist 58:257-331.

Koenig, W. D. 2003. European starlings and their effect on native cavitynesting birds. Conservation Biology 17:1134-1140.

Laskey, A. R. 1946. Snake depredations at bird nests. Wilson Bulletin 58:217-218.

Lima, S. L. 1987. Clutch size in birds: a predation perspective. Ecology 68:1062-1070.

Lima, S. L. 2009. Predators and the breeding bird: behavioral and reproductive flexibility under the risk of predation. Biological Reviews 84:485-513.

Lima, S. L., and L. M. Dill. 1990. Behavioral decisions made under the risk of predation: a review and prospectus. Canadian Journal of Zoology 68:619-640.

Mainwaring, M. C., I. Barber, D. C. Deeming, D. A. Pike, E. A. Roznik, and I. R. Hartley. 2017. Climate change and nesting behavior in vertebrates: a review of the ecological threats and potential for adaptive responses. Biological Reviews 92:1991-2002.

Martin, T. E. 1988. Habitat and area effects on forest bird assemblages: is nest predation an influence? Ecology 69:74-84.

Martin, T. E. 1993. Nest predation and nest sites. BioScience 43:523-532.

Martin, T. E. 1995. Avian life history evolution in relation to nest sites, nest predation, and food. Ecological Monographs 65:101-127.

Martin, T. E., and J. V. Briskie. 2009. Predation on dependent offspring: a review of the consequences for mean expression and phenotypic plasticity in avian life history traits. Annals of the New York Academy of Sciences 1168:201-217.

Martin, T. E., and P. Li. 1992. Life history traits of open- vs. cavitynesting birds. Ecology 73:579-592.

Miller, K. E. 2002. Nesting success of the great crested flycatcher in nest boxes and in tree cavities: are nest boxes safer from nest predation? Wilson Bulletin 114:179-185.

Mönkkönen, M., J. T. Forsman, T. Kananoja, and H. Ylönen. 2009. Indirect cues of nest predation risk and avian reproductive decisions. Biology Letters 5:176-178.

Mouton, J. C., and T. E. Martin. 2018. Fitness consequences of interspecific nesting associations among cavity-nesting birds. American Naturalist 192:389-396.

Němec, M., and R. Fuchs, R. 2014. Nest defense of the red-backed shrike Lanius collurio against five corvid species. Acta ethologica 17:149-154.

Nice, M. M. 1957. Nesting success in altricial birds. Auk 74:305-321.

Nilsson, S. G. 1984. The evolution of nest-site selection among holenesting birds: the importance of nest predation and competition. Ornis Scandinavica 15:167-175.

Palleroni, A., M. Hauser, and P. Marler. 2005. Do responses of galliform birds vary adaptively with predator size? Animal Cognition 8:200-210.

Parejo, D., and J. M. Avilés. 2011. Predation risk determines breeding territory choice in a Mediterranean cavity-nesting bird community. Oecologia 165:185-191.

Parsons, M. H., R. Apfelbach, P. B. Banks, E. Z. Cameron, C. R. Dickman, A. S. K. Frank, M. E. Jones, I. S. McGregor, S. McLean, D. Müller-Schwarze, E. E. Sparrow, and D. T. Blumstein. 2018. Biologically meaningful scents: a framework for understanding predator-prey research across disciplines. Biological Reviews 93:98-114.

Pfeiffer, M. B., T. W. Seamans, B. N. Buckingham, and B. F. Blackwell. 2019. Landscape factors that influence European starlings (Sturnus vulgaris) nest box occupancy at NASA Plum Brook Station (PBS), Erie County, Ohio. USA. Ohio Journal of Science 119:38-47.

Psiropoulos, J. L., and L. A. Selner. 2019. European starlings fly before they fledge. Human-Wildlife Interactions 13:356-359.

Refsnider, J. M., A. M. Reedy, D. A. Warner, and F. J. Janzen. 2015. Do trade-offs between predation pressures on females versus nests drive nest-site choice in painted turtles? Biological Journal of the Linnean Society 116:847-855.

Rendell, W. B., and R. J. Robertson. 1994. Cavity-entrance orientation and nest-site use by secondary hole-nesting birds. Journal of Field Ornithology 65:27-35.

Ricklefs, R. E. 1969. An analysis of nesting mortality in birds. Smithsonian contributions to zoology 9. Smithsonian Institution Press, Washington, D.C., USA. 
Ricklefs, R. E. 1977. Reactions of some Panamanian birds to human intrusion at the nest. Condor 79:376-379.

Ruiz, N. M. D., M. Fasanella, and G. J. Fernández. 2018. Breeding southern house wrens exhibit a threat-sensitive response when exposed to different predator models. Journal of Ethology 36:43-53.

Seamans, T. W., B. F. Blackwell, and L. A. Tyson. 2015. Low occupancy rates of artificial nest cavities by European starlings. Ohio Journal of Science 115:53-55.

Slagsvold, T. 1982. Clutch size variation in passerine birds: the nest predation hypothesis. Oecologia 54:159-169.

Stanback, M. T., C. M. Dove, C. Fonda, P. Parkes, and J. Ptaschinski. 2018. Eastern bluebirds (Sialia sialis) do not avoid nest cavities containing predator odors. Wilson Journal of Ornithology 131: 680-686.

Templeton, C. N., E. Greene, and K. Davis. 2005. Allometry of alarm calls: black-capped chickadees encode information about predator size. Science 308:1934-1937.
Tyson, L. A., B. F. Blackwell, and T. W. Seamans. 2011. Artificial nest cavity used successfully by native species and avoided by European starlings. Wilson Journal of Ornithology 123:827-830.

Weatherhead, P. J., and G. Blouin-Demers. 2004. Understanding avian nest predation: why ornithologists should study snakes. Journal of Avian Biology 35:185-190.

Weatherhead, P. J., G. L. Carfagno, J. H. Sperry, J. D. Brawn, and S. K. Robinson. 2010. Linking snake behavior to nest predation in a Midwestern bird community. Ecological Applications 20:234-241.

Wisenden, B. D., and K. R. Harter. 2001. Motion, not shape, facilitates association of predation risk with novel objects by fathead minnows (Pimephales promelas). Ethology 107:357-364.

Zanette, L. Y., A. F. White, M. C. Allen, and M. Clinchy. 2011. Perceived predation risk reduces the number of offspring songbirds produce per year. Science 334:1398-1401.

Associate Editor: Benson. 